\title{
Very Early Onset Mania with Hypersexuality in a 4.5-Year-Old Child: A Case Report
}

\author{
${ }^{1}$ Subir Bhattacharjee, ${ }^{2}$ Sujit Sarkhel
}

\section{ABSTRACT}

Bipolar mood disorder (BPD) may manifest as the first episode of mania as early as below 6 years old. There are controversies regarding its diagnoses as because of sharing of symptoms with disruptive mood dysregulation disorder (DMDD), attention deficit hyperactivity disorder (ADHD) and conduct disorder. Hypersexuality was found to be a prominent feature in early-onset bipolar disorder (EOBD). Here is a case report of first episode mania in a child of 4.5 years old with a prominent feature of hypersexuality who responded well with valproate and risperidone.

Keywords: Childhood hypersexuality, Childhood mania, Very early onset mania.

How to cite this article: Bhattacharjee S, Sarkhel S. Very Early Onset Mania with Hypersexuality in a 4.5-Year-Old Child: A Case Report. Ind J Priv Psychiatry 2018;12(2):57-58.

\section{Source of support: Nil}

Conflict of interest: None

\section{INTRODUCTION}

Bipolar affective disorder (BAD), characterized by episodes of mania, hypomania, and depression, is one of the leading causes of disability worldwide with a lifetime prevalence of about 1 to $3 \%$ in general population. ${ }^{1}$ Though studies across countries showed that late adolescence and early adulthood are peak years for the onset of bipolar disorder, it is not uncommon in children below 12 years of age. ${ }^{2}$ First episode mania or hypomania is not very common in the pediatric population as EOBD is more likely to manifest as depression. Adult mania is more commonly characterized by euphoria whereas childhood mania is commonly characterized by prominent irritability, anger outburst and psychosis. ${ }^{3}$ Diagnosis of childhood bipolar disorder is controversial because of comorbidities and sharing of symptoms with ADHD, conduct disorder and oppositional defiant disorder. ${ }^{4}$ Case

\footnotetext{
${ }^{1}$ Assistant Professor, ${ }^{2}$ Associate Professor

${ }^{1}$ Department of Psychiatry, Purulia Government Medical College, Purulia, West Bengal, India

${ }^{2}$ Department of Psychiatry, IOP-Center of Excellence, Kolkata, West Bengal, India
}

Corresponding Author: Sujit Sarkhel, Associate Professor, Department of Psychiatry, IOP-Center of Excellence, Kolkata, West Bengal, India, e-mail: sujitsarkhel@gmail.com reports and studies with very early onset bipolar disorder are not very frequent and lacking adequate information regarding its symptoms and characters which can differentiate it from other diagnoses. Here is a case report of very early onset mania with prominent features of hypersexuality in a male child of 4.5 years.

\section{CASE REPORT}

In February 2018, a 4.5-year-old single male child from middle class socio-economic rural family, was presented to a psychiatrist with increased talkativeness, easy irritability, decreased sleep and increased pleasurable activities like playing music on television loudly, dancing excessively and excessive, developmentally precocious, aggressive and socially inappropriate sexual behaviors for last 4 weeks. According to his mother they at first ignored his behavioral changes supposing those to be excessive than normal but later found to be gradually increasing and becoming socially inappropriate and unacceptable. He was playing television loudly, was singing loudly, dancing excessively with music and whenever was opposed or was tried to restrict, he was becoming irritable and sometimes violent and physically abusive to others. His parents became excessively worried when he started to touch other ladies, even unknown to him, inappropriately, trying to kiss them, sometimes asking them to rub his genital area and becoming hard to resist because of his extreme irritability. He had no family history, suggestive of any mood disorder or other psychiatric illness. He was born out of non-consanguineous marriage, delivered normally with appropriate birth weight, having normal developmental history up to age. His physical examination did not reveal any significant abnormality, height and weight were normal. In the mental status examination, he was found to be excessively talkative, easily distractible, increased in psychomotor activity, becoming irritable on the opposition. There were no signs or symptoms of hallucinations and delusions. He was diagnosed to be suffering from 'Bipolar I Disorder, current episode manic, moderate (296.42)' according to diagnostic and statistical manual, fifth edition (DSM-5). His routine blood investigations including liver function test and thyroid functions test were in normal range, and computed tomography (CT) scan of 
the brain was also found to be normal. His score on Young Mania rating scale (YMRS)- parent version was 30, mostly contribution from increased motor activity-energy, sexual interest, irritability, disruptive-aggressive behavior. He was given syrup. sodium valproate $(200 \mathrm{mg} / 5 \mathrm{~mL})$ at a dose of $10 \mathrm{mg} / \mathrm{kg}$ of body weight and syrup risperidone $(1 \mathrm{mg} / \mathrm{mL})$ at a dose of $1 \mathrm{mg}$ in divided doses. At follow-up, after 1 week he showed improvement on P-YMRS scale and his dose of valproate was increased to $15 \mathrm{mg} / \mathrm{kg}$ of body weight. He showed significant improvement after 3 weeks and was advised to continue medicines and for regular follow-up.

\section{DISCUSSION}

There are controversies regarding the diagnosis of childhood bipolar disorder as it is not clear whether the same diagnostic criterion of the adult population is also helpful for children. Some experts recommend following the DSM criteria for the diagnosis of childhood bipolar disorder. This child met the criterion for manic episode according to DSM 5 diagnostic criterion, so was diagnosed accordingly. The typical symptom of mania includes pressured speech, racing thoughts, hypersexuality, and grandiosity which are more often in late adolescence. In childhood or prepubertal onset mania, those classic symptoms are not very common, ${ }^{5}$ though we found increased talkativeness, prominent hypersexuality in our case. The DMDD is one of the differential diagnoses of childhood bipolar disorder. Irritability and anger outbursts associated with DMDD are not episodic rather chronic and constantly displayed on an almost daily basis. ${ }^{6}$ Our case had a distinct period of onset of irritability and other manic symptoms over the last 4 weeks so did not fit for the diagnoses of DMDD. Barbara et al. ${ }^{7}$ reported prominence of hypersexuality $(43 \%)$ when studied phenomenology of mania in a group of 93 children and adolescents diagnosed with bipolar disorder. They proposed hypersexuality as a cardinal feature of childhood mania. Hypersexuality in our case was also supported their view, as it was the main cause of distress in parents and they found it to be appropriate to report to the psychiatrist. Drug of choice for childhood bipolar disorder is lithium but its efficacy below 8 years was not extensively studied..$^{8}$ So we used valproate as it is found to be safe to use in a child over 2 years. Again risperidone also showed efficacy in childhood mania. ${ }^{9}$ With treatment the child showed improvement on P-YMRS scale.

\section{CONCLUSION}

Bipolar disorder may manifest as first episode mania as very early in a 4.5 years old child with a prominent feature of hypersexuality. It can be differentiated from DMDD, ADHD and conduct disorder by the presence of hypersexuality. Valproate and risperidone may be used to treat manic symptoms below 5 years of age.

\section{REFERENCES}

1. Boland EM, Alloy LB. Sleep disturbance and cognitive deficits in bipolar disorder: toward an integrated examination of disorder maintenance and functional impairment. Clinical psychology review. 2013 Feb 1;33(1):33-44.

2. Christie KA, Burke JD, Regier DA, Rae DS, Boyd JH, Locke BZ. Epidemiologic evidence for early onset of mental disorders and higher risk of drug abuse in young adults. The American Journal of Psychiatry. 1988 Aug 1;145(8):971-975.

3. Cosgrove VE, Roybal D, Chang KD. Bipolar depression in pediatric populations. Pediatric Drugs. 2013 Apr 1;15(2):83-91.

4. Leibenluft E, Rich BA. Pediatric bipolar disorder. Annu. Rev. Clin. Psychol.. 2008 Apr 27;4:163-187.

5. Goetz M, Novak T, Vesela M, Hlavka Z, Brunovsky M, Povazan $M$, et al. Early stages of pediatric bipolar disorder: retrospective analysis of a Czech inpatient sample. Neuropsychiatric disease and treatment. 2015;11:2855-2864.

6. Leibenluft EL, Uher RU, Rutter MI. Disruptive mood dysregulation with dysphoria disorder: a proposal for ICD-11. World Psychiatry. 2012 Jun;11(Suppl 1):77-81.

7. Geller B, Tillman R, Bolhofner K, Zimerman B. Child bipolar I disorder: prospective continuity with adult bipolar I disorder; characteristics of second and third episodes; predictors of 8-year outcome. Archives of general psychiatry. 2008 Oct 6;65(10):1125-1133.

8. Vitiello B, Riddle MA, Yenokyan G, Axelson DA, Wagner KD, Joshi P, et al. Treatment moderators and predictors of outcome in the Treatment of Early Age Mania (TEAM) study. Journal of the American Academy of Child \& Adolescent Psychiatry. 2012 Sep 1;51(9):867-878.

9. Geller B, Luby JL, Joshi P, Wagner KD, Emslie G, Walkup JT, et al. A randomized controlled trial of risperidone, lithium, or divalproex sodium for initial treatment of bipolar I disorder, manic or mixed phase, in children and adolescents. Archives of general psychiatry. 2012 May 1;69(5):515-528. 